\title{
Foraging ecologies of giraffe (Giraffa camelopardalis reticulata) and camels (Camelus dromedarius) in northern Kenya: effects of habitat structure and possibilities for competition?
}

\author{
David A. O'Connor ${ }^{1,2,3 *}$, Bilal Butt ${ }^{2}$ and Johannes B. Foufopoulos ${ }^{2}$ \\ ${ }^{1}$ San Diego Zoo Institute for Conservation Research, 15600 San Pasqual Valley Road, Escondido, CA, 92027, U.S.A., ${ }^{2}$ School of Natural Resources \\ and Environment, University of Michigan, 440 Church St. Ann Arbor, Michigan, 48109-1041, U.S.A. and ${ }^{3}$ National Geographic Society 1145 \\ 17th St., NW, Washington, DC, 20036, U.S.A.
}

\begin{abstract}
The foraging ecologies of reticulated giraffe (Giraffa camelopardalis reticulata) and domestic camels (Camelus dromedarius) were examined in the Laikipia District of Kenya, where these species have recently become sympatric. Camels increased popularity in the region has lead to concerns about their environmental impacts and possible competition with wild giraffe for resources. We gathered foraging data on both species using 2-min group scans that recorded feeding heights and plant food preferences. Transects sampled the vegetation in areas where foraging observations were recorded. Giraffe females feed at lower elevations than males, while female camels feed below both sexes of giraffe. There was very little observed overlap in food preferences between the species. However, habitat type has an effect on foraging ecologies of both giraffe sexes, but habitat did not influence camel foraging. Camel herder husbandry techniques also influence camel foraging dynamics. These findings have important implications in achieving the twin objectives of wildlife conservation and pastoralist livestock production in northern Kenya.
\end{abstract}

Key words: camel, conservation, foraging ecology, giraffe, pastoralist

\section{Résumé}

L'écologie alimentaire de la girafe réticulée (Giraffa camelopardalis reticulata) et celle du dromadaire (Camelus dromedarius) ont été étudiées dans le District de Laikipia,

*Correspondence: E-mail: doconnor@sandiegozoo.org au Kenya, où ces espèces sont récemment devenues sympatriques. La popularité croissante des dromadaires dans la région a suscité des inquiétudes au sujet des impacts sur l'environnement et d'une éventuelle compétition pour les ressources avec les girafes sauvages. Nous avons récolté des données sur l'alimentation des deux espèces au moyen de scan de groupe de deux minutes, qui enregistraient la hauteur à laquelle les animaux mangeaient et les plantes préférées. Des transects ont permis de récolter des échantillons de végétation dans les zones où les observations alimentaires ont été faites. Les girafes femelles se nourrissent plus bas que les mâles et les dromadaires femelles se nourrissent plus bas que les girafes des deux sexes. Nous avons observé très peu de recouvrement des préférences alimentaires des deux espèces. Le type d'habitat a un effet sur l'écologie alimentaire des girafes des deux sexes mais il n'influence pas l'alimentation des dromadaires. Les techniques d'élevage des dromadaires influencent aussi la dynamique alimentaire des dromadaires. Ces résultats ont d'importantes implications pour atteindre le double objectif de la conservation de la faune sauvage et de la production d'un bétail pastoral dans le nord du Kenya.

\section{Introduction}

Eastern Africa's semi-arid ecosystems exhibit dynamic interactions between pastoralist cultures, wildlife, complex rainfall patterns and soil types (Kjekshus, 1996). This includes 46 extant free-ranging ungulate species (Owen-Smith \& Cumming, 1993), as well as three dominant 
livestock species: cattle (Bos spp.), goats (Capra hircus) and sheep (Ovis aries). African herbivores are categorized into a browsing and a grazing guild (du Toit, 1995); within each guild, coexisting species tend to have differing body sizes and feeding strategies (Woolnough \& du Toit, 2001). With such complexity, it is vital to better understand how shared food resources partitioned among coexisting species (Sinclair, 1979; Butt \& Turner, 2012).

Competition between herbivores depends on numerous factors, and African ungulate guilds partition existing plant resources along temporal and spatial axes (McNaughton \& Georgiadis, 1986; du Toit, 1990). Considering the spatial axis, browser species maximize nutritional and energetic intake by focusing their feeding on different heights of vegetation (Pellew, 1984; Cameron \& $\mathrm{du}$ Toit, 2007). Although there is a clear stratification in feeding preferences, overlap does exist (du Toit, 1990). Such overlap in resource usage sets the stage for possible competition for browse resources (see Prins \& Fritz (2008)).

Pastoralist livestock systems occur across much of the East African savannah, with livestock herds often overlapping spatially with wild herbivores, and utilizing the same resources. In areas where such livestock grazing occurs, it represents an added layer of pressure on the vegetation available for wild herbivores. Livestock feeding and husbandry could have significant knock-on effects on the functioning and structure of the savannah system, as well as on the availability of browse (Butt \& Turner, 2012).

However, a species that exists alongside people, livestock and wild ungulates - the giraffe (Giraffa camelopardalis reticulata de Winston) - has been thought to escape such resource overlap with either wildlife or livestock (Ciofolo \& Le Pendu, 2002). This is primarily due to giraffe's capacity to feed on vegetation out of reach of other ruminants, and its ability to travel long distances in search of forage (du Toit, 1990; Young \& Isbell, 1991; Bond \& Loffell, 2001; Woolnough \& du Toit, 2001; Parker \& Bernard, 2005; Fennessy, 2009).

Pastoralist herders aim to manage their livestock for maximum productivity with respect to environmental conditions (Galvin, 1992; Ellis \& Galvin, 1994; Galvin, Coppock \& Leslie, 1994). Changes in climate and more frequent droughts represent a serious challenge to African pastoralists (Davies \& Bennett, 2007; Homewood, 2008; Butt, 2010; Kiage, 2013). One way pastoralists have dealt with aridity in some environments is to change herd composition from cattle-dominated groups to including sheep and goats or even camels (Camelus dromedarius
Linnaeus). Domestic camels are more drought tolerant than cattle, performing well in adverse conditions, and have lower energy requirements (Farid, 1995; Maloiy, Rugangazi \& Rowe, 2009).

Camel foraging is under studied (Dereje \& Uden, 2005). Few studies exist currently on the effects of introduced camels on ecosystem function and the resident herbivore communities. Camel browsing may affect forage availability, vegetation composition or structure. One particularly important relationship could exist between domestic camels and reticulated giraffe. Both are large ungulate browsers, with the ability to feed across a large vertical spectrum.

This research explores the foraging preferences of domestic camels and wild reticulated giraffe by investigating:

1 Is there overlap between camel and giraffe feeding heights and preferred plant food species?

2 Are there differences between adult female and adult male giraffe foraging ecologies across habitat types?

\section{Methods}

\section{Study area}

Field data were gathered between May and August 2011 on the 19,873 ha Mpala Research Centre (MRC) in Laikipia Province (north central Kenya). Camels are kept as livestock at MRC, providing the opportunity to compare the foraging ecologies of domestic camel and the coexisting wild reticulated giraffe.

Camels are managed at MRC in a quasi-pastoralist fashion; herded during the day, and returning each evening to a boma (temporary animal enclosures built either of cut acacia branches or of mobile metal fencing).

Western Mpala is composed of topographically flat, 'black cotton' vertisol (clay) soils characterized by extreme shrink-swell movements, that destroy the roots of most plant species (Pringle et al., 2010). This produces a low diversity savannah with $97 \%$ over story cover of Acacia drepanolobium Harms ex Y. Sjöstedt, and ground cover composed of five grass species and two forbs (Young, Stubblefield \& Isbell, 1997; Young et al., 1998).

Eastern and northern Mpala is composed of infertile red sandy loams (alfisols; locally termed 'red soil'). This soil type supports a diverse, structurally variable bushland habitat with a patchy understory of perennial grasses, and a canopy cover dominated by A. brevispica Harms, A. mellifera Benth and A. etbaica Schweinf (Augustine \& McNaughton, 2004; Kinnaird \& O’Brien, 2012). 
Between these areas is a transition zone, which supports a savannah dominated by perennial grasses with widely spaced shrubs, including species from both the black cotton and red soil habitats (see Fig. 1). These three soil types produce vegetation types that are very different in species richness, and result in distinct habitat structures (Augustine \& McNaughton, 2004; Kinnaird \& O'Brien, 2012), allowing for comparison with herbivore foraging ecology across these three soil types.

\section{Behavioural observations}

To determine overlap in feeding height and plant food species preferences between giraffe and camels, spatially explicit 2-min behavioural group scans (Altmann, 1974; Bøving \& Post, 1997; Hamel \& Cote, 2008; Treydtea et al., 2011) were used to record frequency of feeding at different height categories, as well as the frequency of feeding on

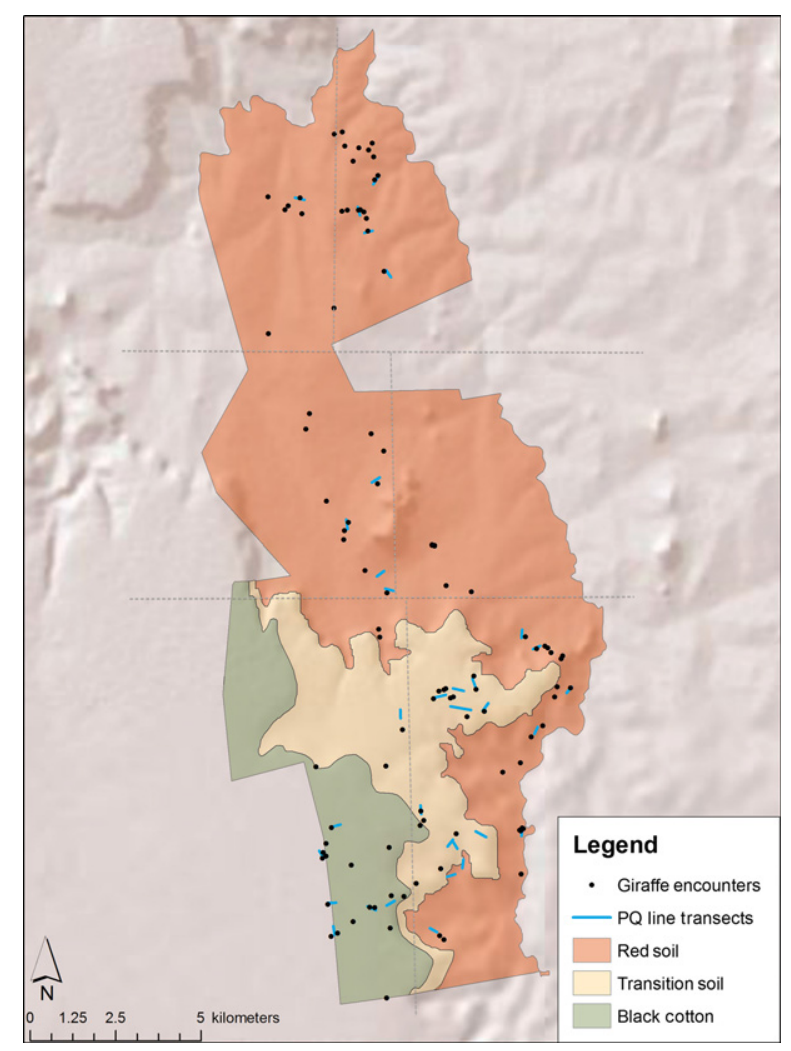

Fig 1 Map of study area (19,873 ha), showing the three primary soil types, giraffe encounters, and vegetation transect lines. Grey lines outline the six sampling sections. Projection: USGS 1984 UTM 37N. Source: The Mpala Research Centre, Nanyuki Kenya (soil type), BingMaps aerial (2010) plant species (See Fig. S1, Tables S1 and S2). Only data from adult giraffe and adult female camels are included here. Male camels were not observed due to low stocking numbers and field time limitations.

\section{Reticulated giraffe surveys and observations}

Giraffe were surveyed between 6:30 am and 11:00 am and again from 3:00 pm to sunset, to avoid the midday period when animals are least active (Pellew, 1984). Observations were vehicle-based for safety and to minimize disturbance. The study area was divided into six sections (Fig. 1) that were visited in rotation to allow for even distribution of sampling effort across MRC.

When giraffe were encountered a GPS waypoint, the number and sex of visible giraffe were recorded. The distance to the giraffe was measured by a laser rangefinder, and the bearing angle was taken using a handheld compass. This allowed for exact positioning of the giraffe in the landscape using GIS trigonometry functions (ArcGIS 10, Fig. S2). When the encounter ended, the GPS location, distance and compass bearing to the group/animal's last location were again recorded. This allowed for straight-line approximation of the giraffe's browsing movement (vectoring) through the landscape.

To quantify giraffe feeding heights, four feeding height categories were assigned based on the angle subtended between the neck and forelegs (Fig. 2): feed high $180^{\circ}$, feed medium $135^{\circ}$, feed level $90^{\circ}$ and feed below $45^{\circ}$ (du Toit, 1990). The actual heights of each feeding category were measured on plants (du Toit pers. comm.). After observing a giraffe foraging at one of the height categories on a plant, that same plant was visited after the giraffe's departure and the bite mark height above ground level was measured using wooden poles marked in 50-cm increments (Fig. 2 and Table S3).

\section{Camel surveys and observations}

Observations were made on the single accessible herd of camels over five days. The herd consisted almost exclusively of adult, breeding females, with between 3 and 5 males, as well as several young and juveniles. The observer walked with the herders amidst the camels as they foraged across the landscape.

Scan observations were conducted in 1-h increments, followed by a break to avoid observer fatigue. A GPS waypoint was taken at the beginning and end of each of 

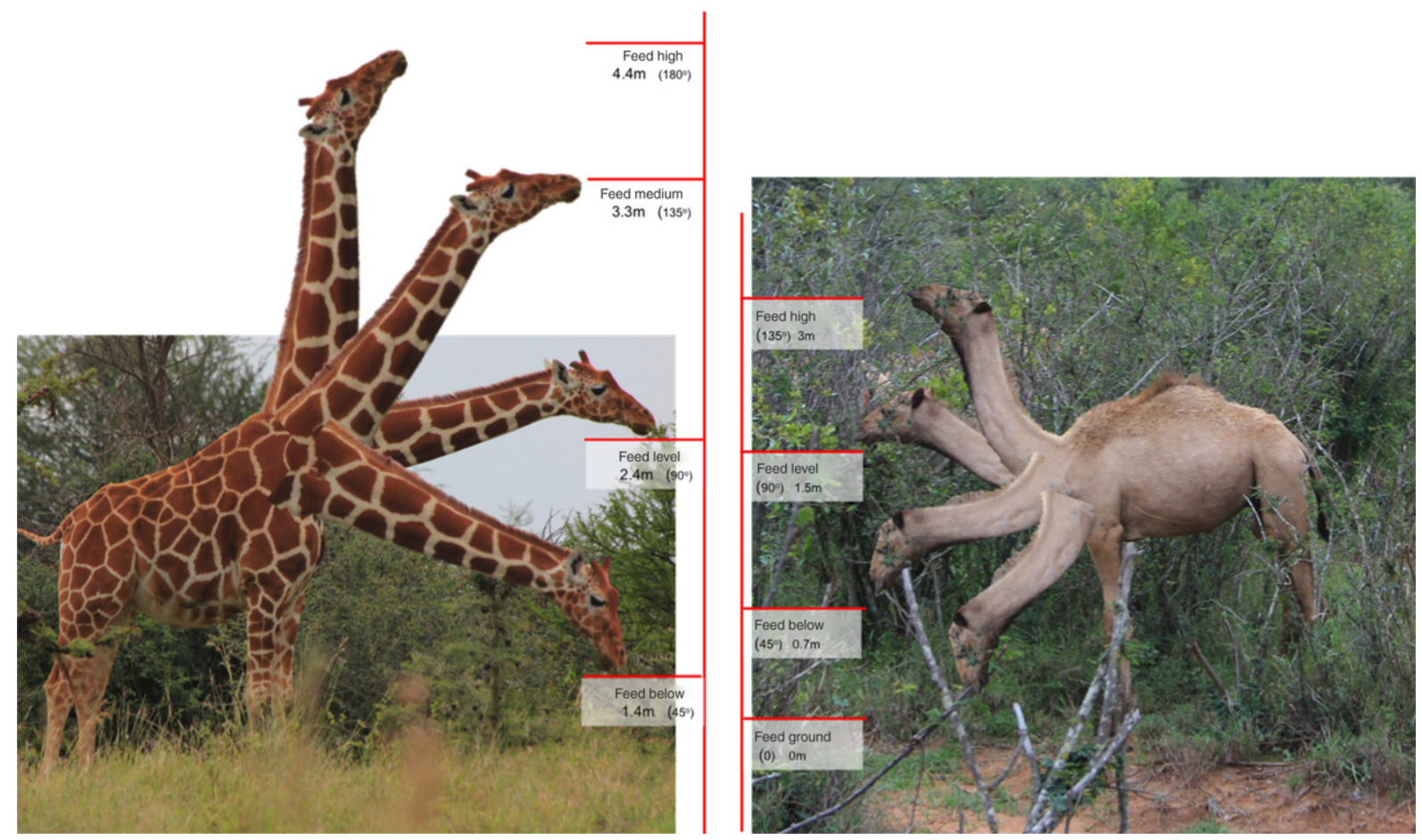

Fig 2 Photo illustration showing the giraffe and adult female camel feeding height categories and neck angles. (Not to scale. Giraffe and camel in photo illustrations are based on images of adult females)

the hour-long observation periods. This allowed for vectoring of the movement of the camel herd during the observation periods, as well as for comparisons with giraffe.

For each 2-min group scan, observations were recorded of the first twenty adult female camels seen, although this number was reduced to fifteen after the first three days of observations, due to the difficulty of recording 20 camels at a time. Observations were not made during periods of active herding.

Camel feeding height categories are based on the angle subtended between the neck and forelegs (Fig. 2): feed high $135^{\circ}$, feed level $90^{\circ}$, feed below $45^{\circ}$ and feed ground (grazing). To measure the height of each of the feeding height categories, the heights above ground of the heads of fifteen adult female camels were measured when held approximately at middle of each category (head held high, shoulder level and knee level) while in the boma (du Toit pers. comm.).

\section{Vegetation transects}

To measure the vertical structure and relative density of plant species, 33 transects were conducted along observed browsing vectors of giraffe and camels (Fig. 1) to allow sampling of the vegetation and habitat structure that the animals browsed in. Each transect had a minimum length of $250 \mathrm{~m}$. Point-centred quarter samples (PQ samples) were taken every $25 \mathrm{~m}$ along the transect line (Pellew, 1983; Young \& Isbell, 1991; Cornelissen et al., 2003; Mitchell, 2007) so that there was a maximum of ten $P Q$ samples per transect. In each PQ quarter, the distance to the branch end of the nearest live woody plant taller than $0.8 \mathrm{~m}$ was measured using a 100-m tape measure. The height of the plant was also measured to the end of its highest branch using a fibreglass telescoping tree measurement pole.

\section{Statistical analysis}

For comparison of feeding heights within and between species, pooling and then averaging each animal's feeding height data over the observation period minimized the possibility of nonindependence of observations. This resulted in a single averaged feed height for each animal for each observation period. For encounters with large herds, where observations were not tracked to individuals 
-the aforementioned 'animals' may not have been the same individual, and in such cases, they were categorized as composite animals (Table S5).

To examine the foraging overlap between camel and giraffe, unaveraged feeding height data were used to analyse the feeding heights on plant species (Tables 1 and 2). As such, those results should be interpreted with caution due to the possibility that the data are not independent.

Data were tested for normality using the Shapiro-Wilk test. Nonparametric tests were used for non-normal data. The feeding heights of camels and giraffe on plant species were analysed using Mann-Whitney U-tests. Multiway ANOVAs and Tukey's HSD pairwise comparisons were used to determine the influence of habitat type and sex on the feeding heights of giraffe, using summarized data.

\section{Results}

\section{Occurrence and feeding height categories}

Feeding height data $(\mathrm{n}=3617)$ were recorded for 337 giraffe across 85 encounters (Fig. 1 and Table S6). However, these may not all be unique individuals, as a given giraffe may have been repeatedly sighted on different days.

Female camel herd size varied between 62 and 78 individuals. Our survey produced 7340 feeding data observation points (Table S7).

Figure 2 (Tables S3 and S4) shows the results of the giraffe and camel feeding category measurements.

\section{Giraffe and Female camel feeding height comparison}

Average feeding height data were compared between giraffe $(n=337$, individual feed height $\bar{x}=3.0 \mathrm{~m})$ and camels $(n=340$, individual feed height $\bar{x}=1.36 \mathrm{~m}$ ). Female camels fed significantly lower than giraffe (Mann-Whitney U-test, $U=2567, P<0.001$ ) (Fig. 3). This difference remained significant $(U=2538.5$, $P<0.001)$ even after the giraffe observations from black cotton habitat were removed (giraffe $\mathrm{n}=284$, median individual average feed height $=2.93 \mathrm{~m}$ ).

When camel feed heights were separately compared to male $(\mathrm{n}=129)$ and to female giraffe feeding heights $(\mathrm{n}=155)$, camels still feed significantly lower than male giraffe $(U=34.5, \quad P<0.001)$ and female giraffe $(U=2504, P<0.001)$ (Fig. 3).

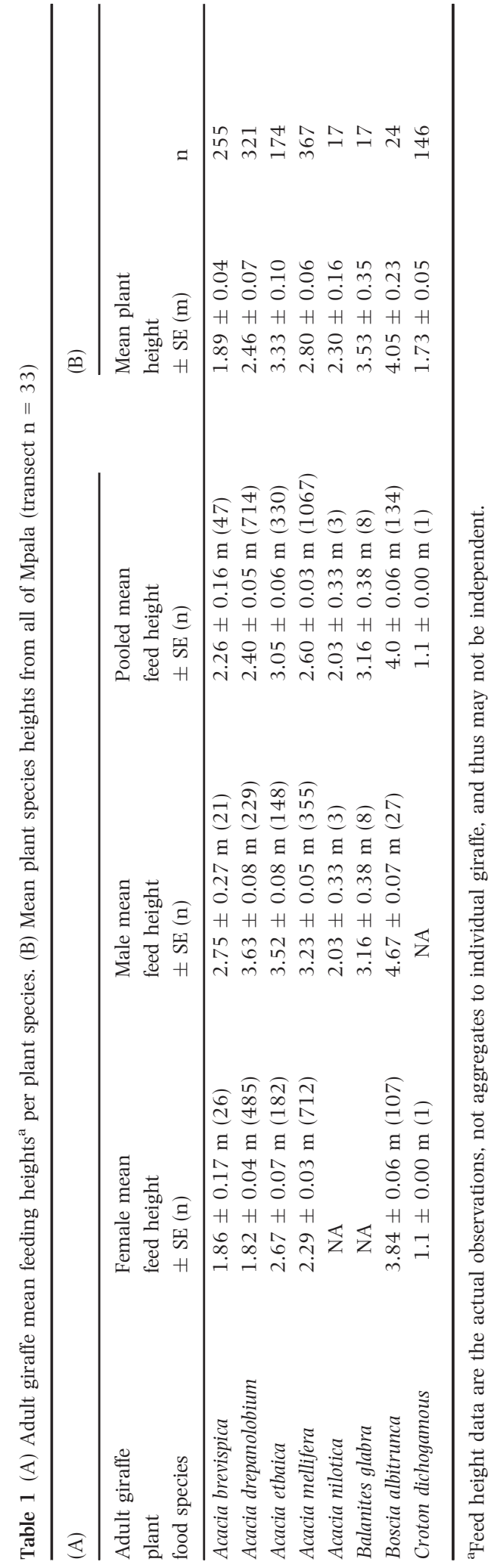




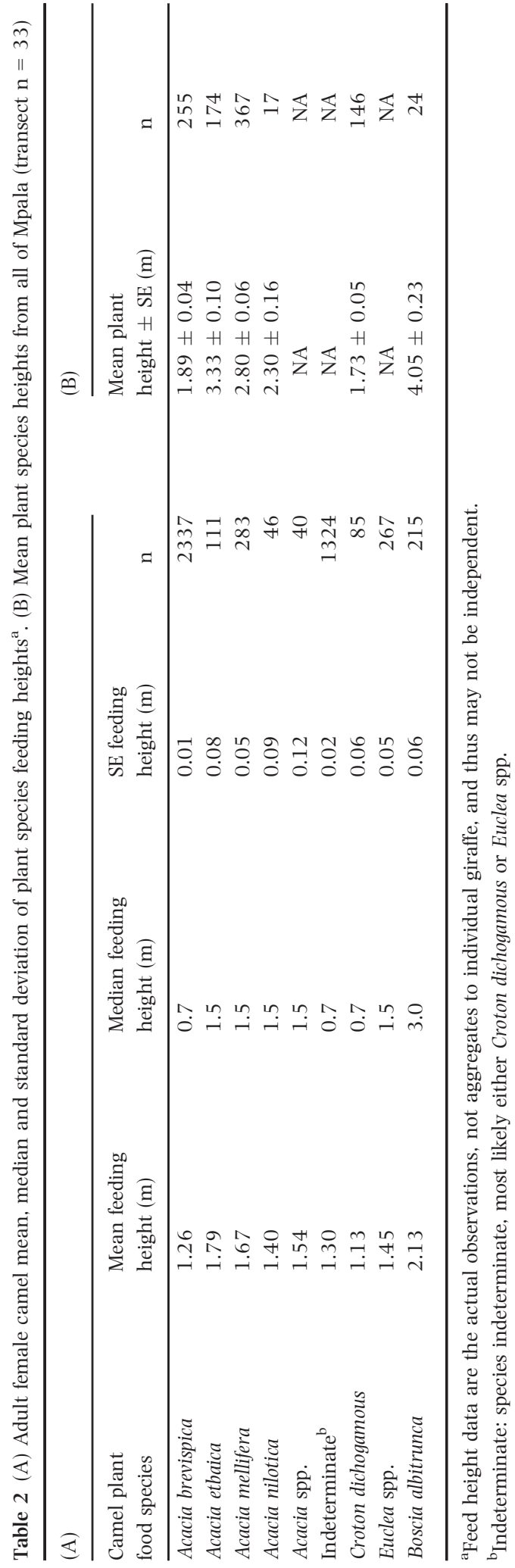

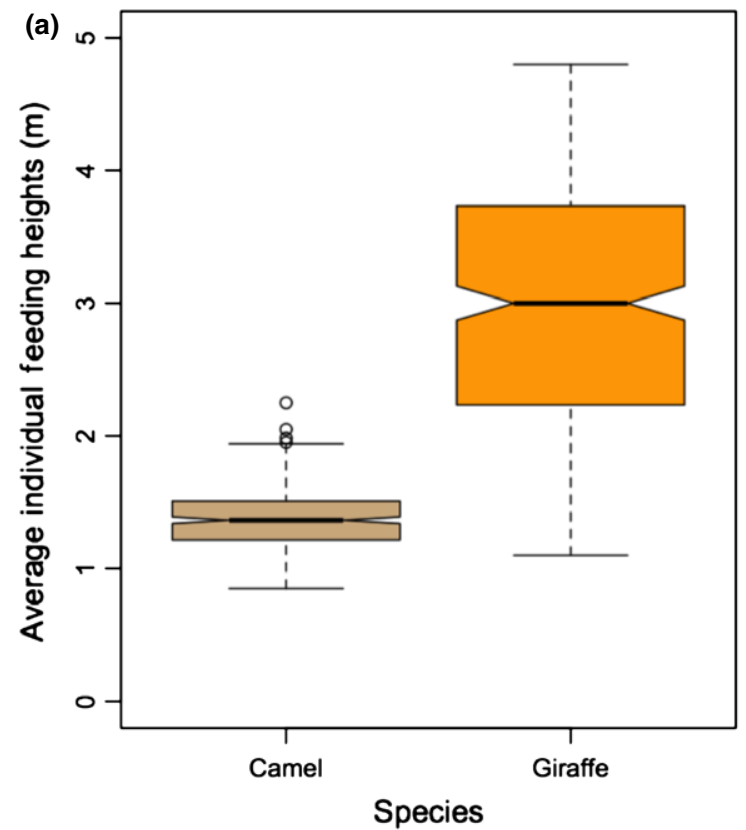

(b)

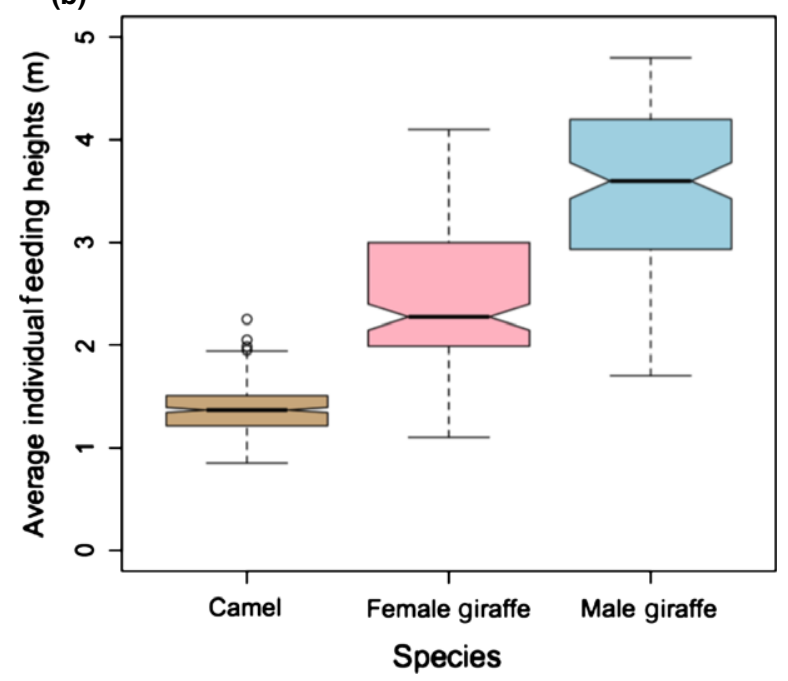

Fig 3 (a) Mean composite individual camel and giraffe feeding heights. Camels fed lower than giraffe (Mann-Whitney U, U = 2567, P < 0.001). (b) Mean composite individual camel and giraffe (male and female) feeding heights. Camels fed lower than both male $(\mathrm{U}=34.5, \mathrm{P}<0.001)$ and female giraffe $(\mathrm{U}=2504$, $\mathrm{P}<0.001)$. Thick indented line represents median values, colored areas show the range of the upper and lower quartile. Range of the minimum and maximum values (excluding outliers) are shown by the dashed lines. Empty circles indicate the outliers

To investigate whether differing habitat structure might explain these differences, the plant transects taken along giraffe browsing paths (transect $\mathrm{n}=22$, plant $\mathrm{n}=968$ ) 
from red soil and transition soil habitat were compared to the plant transects taken along camel browsing vectors (transect $\mathrm{n}=5$, plant $\mathrm{n}=220$ ). The median height of the vegetation along camel browsing vectors $(\theta=1.75 \mathrm{~m})$ was significantly lower than that of giraffe browsing paths $(\theta=2.18 \mathrm{~m})$ using Mann-Whitney $U$-test $(U=81296.5$, $P<0.001)$.

\section{Influence of habitat type and sex on adult giraffe foraging}

Giraffe exhibit a significant difference in average feeding heights between males and females. Males feed on average at $3.7 \mathrm{~m}$ while females feed at $2.5 \mathrm{~m}$ (ANOVA $\left.F_{1,331}=254.7, P<0.001, \mathrm{n}=337\right)$. Indeed, across all three habitat types, male average feeding heights remained significantly higher than female (black cotton: ANOVA $F_{1,51}=48.0, P<0.001$; red soil: ANOVA $F_{1,199}=135.3$, $P<0.001$; transition soil: ANOVA $F_{1,81}=102.1$, $P<0.001$ ) (Fig. 4).

Habitat had a significant effect on giraffe feeding (ANOVA $\left.F_{2,331}=90.3, P<0.001\right)$. The median heights of vegetation in each habitat were significantly different (Kruskal-Wallis $\mathrm{H}=79.6, \quad P$-value $<0.001$ ). Average feeding heights were highest in the black cotton soil and lowest in the transition soil, for both sexes, mirroring the pattern of median vegetation heights.

Males exhibited significant differences in their average feeding heights across all three habitat types (ANOVA
$\left.F_{2,151}=44.8, \quad P<0.001\right) . \quad$ Females showed some similar significant differences (ANOVA $F_{2,180}=46.9$, $P<0.001)$; however, there was no difference between adult female feeding heights in the black cotton and red soil habitats (Tukey's HSD $P=0.09$ ), but that they were significantly lower in transition soil $(P<0.001)$ (Fig. 4).

\section{Giraffe food plants}

Adult giraffe were observed to feed on eight identified woody plant species across Mpala (Table 1), whereas plant transects recorded fifteen species of woody plants (Table S8).

Further analysis was conducted on the four plant species with the most feeding observations (A. mellifera, A. drepanolobium, A. etbaica and Boscia albitrunca Gilg \& Gilg-Ben). Male giraffe consistently feed significantly above the median height of the plant for A. drepanolobium (MannWhitney U-test, $U=17,371, \quad P<0.001)$, but the difference is not significant for $A$. etbaica $(P=0.1)$ or B. albitrunca $(P=0.052)$.

In contrast, female giraffe feed significantly below the median heights of A. drepanolobium (Mann-Whitney $U$-test, $\quad U=106765.5, \quad P<0.001)$ and $A$. etbaica $(U=20,153, \quad P<0.001)$, but not for $B$. albitrunca $(P=0.4)$.

Only A. mellifera was found in all three habitat types, and it showed a significant difference in its median height

Fig 4 Mean composite individual giraffe feeding heights across the three soil types. Male average feeding heights are significantly higher than female (ANOVA - Black Cotton: $\mathrm{F}_{1,51}=48.0$; Red Soil: $\mathrm{F}_{1,199}=$ 135.3; Transition Soil: $\mathrm{F}_{1,81}=102.1$, all $\mathrm{P}<0.001)$. Thick indented line represents median values, colored areas show the range of the upper and lower quartile. Range of the minimum and maximum values (excluding outliers) are shown by the dashed lines. Empty circles indicate the outliers

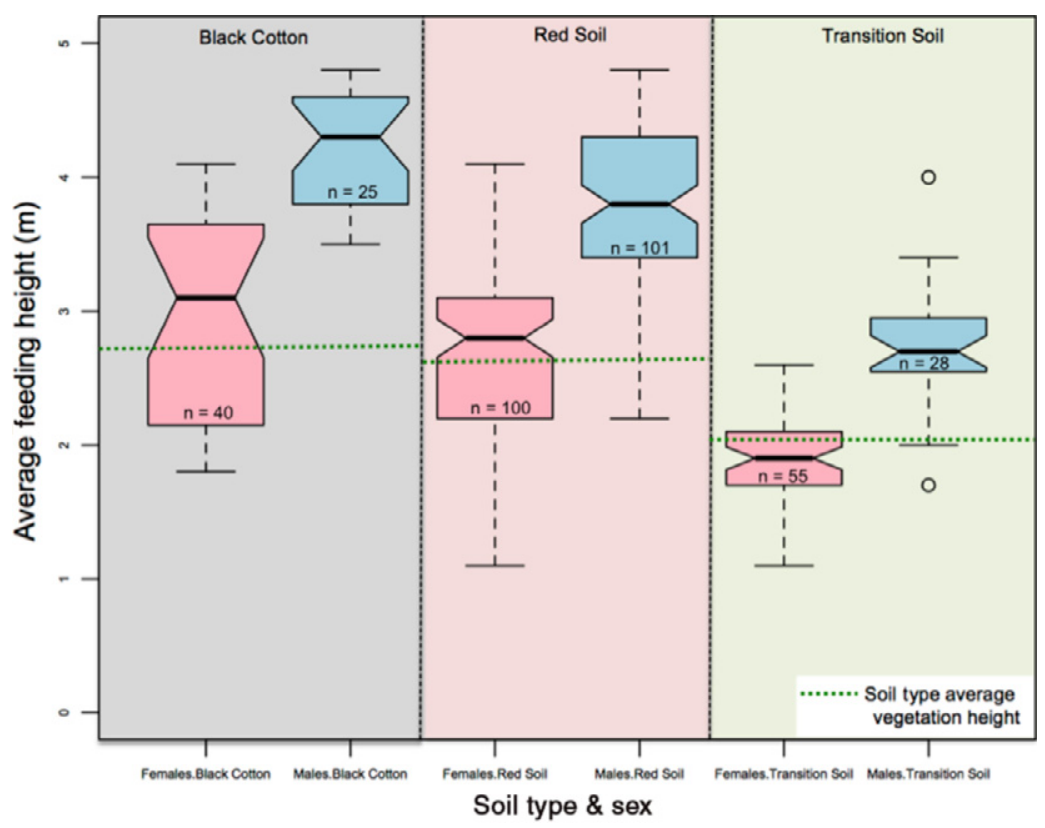


across habitats (Kruskal-Wallis $\mathrm{H}=20.4, \quad P$-value $<0.001)$, except for between black cotton and transition soil $(P$-value $=0.3)$. Overall, female giraffe feed significantly lower than the median height of A. mellifera (MannWhitney $U$-test, $U=164,377, P<0.001$ ), while males feed significantly higher (Mann-Whitney U-test, $U=48420.5, P<0.001$ )

In the black cotton soil, females do not feed higher than the median height of the plant (Mann-Whitney U-test, $U=224, P=0.09$ ), but it is a small sample size (plant height $\mathrm{n}=15$, feeding height observations $\mathrm{n}=45$ ). In red soils, females feed significantly above the median plant height (Mann-Whitney U-test, $U=16,593, P<0.001$ ). While in the transition soils, females feed significantly below the height of the plant (Mann-Whitney U-test, $U=46101.5, P<0.01)$. Males on the other hand feed significantly higher than A. mellifera's median height in all habitats (black cotton: $U=10$; red soil: $U=13,837$; transition soil: $U=8807$, all $P<0.001$ ).

\section{Camel food plants}

Camels were observed to feed on six identified species (Table 2). Three additional plant categories were not identified to species level. Average feeding heights ranged from 1.13 to $2.13 \mathrm{~m}$. Ground level feeding was removed from analysis due to their zero height value.

The four most frequently fed upon plant species were analysed further. Camels fed significantly below the heights of A. brevispica (Mann-Whitney $U$-test, $U=462,318$, $P<0.001)$, A. mellifera $(U=80,223, P<0.001)$, A. etbaica $(U=16,005, P<0.001)$ and $B$. albitrunca $(U=4525$, $P<0.001)$.

\section{Discussion}

Results suggest no direct overlap in the feeding heights of adult female camels and adult giraffe of either sex (Fig. 3). Giraffe and camel do overlap in consumption of six plant species on Mpala, but of the four most frequent species eaten by each, overlap only occurs with $A$. mellifera (Tables 1 and 2). Although A. mellifera makes up 44\% of a giraffe's foraging compared to $6 \%$ of a camel's. Using frequency as an indicator of preference at Mpala, giraffe and female camel prefer two very different plant palettes (see Tables 1 and 2). Similarly, feeding is concentrated at different mean heights, $3.0 \mathrm{~m}$ for giraffe and $1.36 \mathrm{~m}$ for female camels (Fig. 3a).
Another explanation for the divergence in giraffe and camel food preferences is that vegetation densities are different where camels foraged compared to areas where giraffe foraged. The overall height of camel-fed vegetation was significantly lower than the height of giraffe-fed vegetation. The relative and absolute densities of plant species in the camel's foraging areas also differed compared to densities of plants where giraffe fed. The densities of A. brevispica and B. albitrunca were higher where camels fed, while A. etbaica and A. mellifera were lower. Thus vegetation structure may be driving the differences in preference between camels and giraffe rather than preference.

Previous research from Ethiopia has shown similar camel plant food preference results to those found in this study. They found that during the wet season A. brevispica is the camel's favourite food item (22\% of diet), while A. mellifera is less favoured $(8 \%)$ and Boscia spp. $(<1 \%)$ is rarely eaten (Dereje \& Uden, 2005). These findings mirror those of our study (Table 2). Potentially, these camel plant food preferences could be widespread, and not a peculiarity of plant densities at Mpala.

However, human management practices influence foraging dynamics of camels (Farah et al., 2004; Dereje \& Uden, 2005; Gallacher \& Hill, 2006a). Herders dictate the plant community camels have access to, which may also affect how camels browse. In addition, camel bomas are relocated periodically once the surrounding vegetation is degraded. If a boma is moved to a location with vastly different habitat structure, then that may alter the camels foraging ecology. Further research examining the foraging response of camels to herder influence or changed boma locations could uncover whether camel's preferences are innate or a response to the vegetation structure and densities of their localized habitat and husbandry techniques.

Foraging by camels has been shown to impact plant community composition (El-Keblawya, Ksiksi \& El Alqamy, 2009), they can drive a shift from Acacia savannah to low dwarf scrub (Gallacher \& Hill, 2006b). How the plant community at Mpala will respond to camel browsing is unknown, as is the extent of any knock-on effects on giraffe and other wild herbivore communities, especially because camel distribution is patchy and boma centric at Mpala.

Interest is growing among pastoralist communities to raise camels as livestock to diversify their herds in the face of uncertainty and to maximize livestock production (Desta \& Coppock, 2000; Young et al., 2013; Kinnaird, M. \& O'Brien, T. pers. comm.). Understanding the effects of 
increased camel populations on arid rangelands and their effect on availability of browse for wildlife (including giraffe) is invaluable to inform effective management and continued sustainable livestock-wildlife interactions (Retzer, 2006). This management is critical as giraffe populations are declining (Tutchings et al., 2013), and the impacts of large herbivores on this ecosystem are complex and often counterintuitive (Pringle et al., 2011).

Giraffe and camel have a wide vertical choice when foraging, and these results show an absence of foraging height overlap with each other. More data are needed to determine whether the drivers of these differences are the result of different vegetation communities where these animals are foraging, or are due to differential preferences by the two species. There is pressing need for further research, especially if pastoralist and ranching management trends continue to bring these two large, iconic and fascinatingly complex ungulates together.

\section{Acknowledgements}

This research was funded by several University of Michigan Institutions: the Graham Environmental Sustainability Institute, the School of Natural Resources and Environment, the International Institute, the African Studies Center, the Department of Afroamerican and African Studies, and the Rackham Graduate School. Explorer's Club provided additional support. Sincere gratitude to Adam Ford, Johan du Toit, Michael Stastny, John Doherty, Mpala Research Centre and others who provided expert input and facilitated fieldwork.

\section{References}

Altmann, J. (1974) Observational study of behavior: sampling methods. Behaviour 49, 227-267.

Augustine, D.J. \& McNaughton, S.J. (2004) Regulation of shrub dynamics by native browsing ungulates on East African rangeland. J. Appl. Ecol. 41, 45-58.

BoND, W.J. \& LOFFELL, D. (2001) Introduction of giraffe changes acacia distribution in an South African savanna. Afr. J. Ecol. 39, 286-294.

Bøving, P.S. \& PosT, E. (1997) Vigilance and foraging behaviour of female caribou in relation to predation risk. Rangifer 7, 55-63.

ButT, B. (2010) Pastoral resource access and utilization: quantifying the spatial and temporal relationships between livestock mobility, density and biomass availability in southern Kenya. Land Degrad. Dev. 21, 520-539.

ButT, B. \& TuRNER, M.D. (2012) Clarifying competition: the case of wildlife and pastoral livestock in East Africa. Pastoralism 2, 9.
CAmeron, E.Z. \& Du Toit, J.T. (2007) Winning by a neck: tall giraffes avoid competing with shorter browsers. Am. Nat. 169, 130-135.

Ciofolo, I. \& Le Pendu, Y. (2002) The feeding behaviour of giraffe in Niger. Mammalia 66, 183-194.

Cornelissen, J.H.C., Lavorel, S., Garnier, E., Diaz, S., Buchmann, N., Gurvich, D.E., Reich, P.B., ter Steege, H., Morgan, H.D., van der Heijden, M.G.A., Pausas, J.G. \& Poorter, H. (2003) A handbook of protocols for standardized and easy measurement of plant functional traits worldwide. Aust. J. Bot. 51, 335-380.

DAvies, J. \& BenNeTT, R. (2007) Livelihood adaptation to risk: constraints and opportunities for pastoral development in Ethiopia's Afar region. J. Dev. Stud. 43, 490-511.

DeREJE, M. \& UdEN, P. (2005) The browsing dromedary camel I. Behaviour, plant preference and quality of forage selected. Anim. Feed Sci. Tech. 121, 297-308.

Desta, S. \& Coppock, L. (2000) Pastoral system trends and small ruminant production in the Borana Plateau of southern Ethiopia. The Opportunities and Challenges of Enhancing Goat Production in East Africa: Proceedings of a Conference Held at Debub University, Awassa, Ethiopia From November 10 to 12, 2000 (Eds R. C. Merkel, G. Abebe and A. L. Goеtsch). E (Kika) de la Garza Institute for Goat Research, Langston, OK.

ELLIS, J. \& Galvin, K.A. (1994) Climate patterns and land-use practices in the dry zones of Africa. Bioscience 44, 340-349.

El-Keblawya, A., Ksiksi, T. \& El AloAmy, H. (2009) Camel grazing affects species diversity and community structure in the deserts of the UAE. J. Arid Environ. 73, 347-354.

Farah, K.O., Nyariki, D.M., Ngugi, R.K., Noor, I.M. \& Guliye, A.Y. (2004) The Somali and the camel: ecology, management and economics. Anthropologist. 6, 45-55.

FARID, M.F.A. (1995) Nutrient requirements of dromedary camels: protein and energy requirements for maintenance. J. Arid Environ. 30, 207-218.

FenNessy, J. (2009) Home range and seasonal movements of Giraffa camelopardalis angolensis in the northern Namib Desert. Afr. J. Ecol. 47, 318-327.

GaLlacher, D.J. \& HiLl, J.P. (2006a) Effects of camel vs oryx and gazelle grazing on the plant ecology of the Dubai Desert Conservation Reserve. In: Reclaiming the Desert: Towards a Sustainable Environment in Arid Lands (Ed. A. M. O. МонAmed) Proceedings of the Third Joint UAE-Japan Symposium on Sustainable GCC Environment and Water Resources, Abu Dhabi, 28-30 January 2006 Taylor \& Francis, Abu Dhabi, UAE.

GALLACHER, D.J. \& HiLL, J.P. (2006b) Effects of camel grazing on the ecology of small perennial plants in the Dubai (UAE) inland desert. J. Arid Environ. 66, 738-750.

GaLVIN, K.A. (1992) Nutritional ecology of pastoralists in dry tropical Africa. Am. J. Hum. Biol. 4, 209-221.

Galvin, K.A., Coppock, D.L. \& LeSLIE, P.W. (1994) Diet, nutrition and the pastoral strategy. In: African Pastoralist Systems: An Integrated Approach (Eds E. Fratkin, K. A. Galvin and E. A. Roth). L. Rienner Publishers, Boulder CO. 
Hamel, S. \& Cote, S.D. (2008) Trade-offs in activity budget in an alpine ungulate: contrasting lactating and nonlactating females. Anim. Behav. 75, 217-227.

Homewood, K. (2008) Ecology of African Pastoralist Societies. Ohio University Press, Athens, OH, James Currey, Oxford.

Kiage, L.M. (2013) Perspectives on the assumed causes of land degradation in the rangelands of Sub-Saharan Africa. Prog. Phys. Geog. 37, 664-684.

KinNAIRD, M.F. \& O'BriEn, T.G. (2012) Effects of private-land use, livestock management, and human tolerance on diversity, distribution, and abundance of large African mammals. Conserv. Biol. 26, 1026-1039.

KJEKSHUS, H. (1996) Ecology Control E Economic Development in East African History: The Case of Tanganyika, 1850-1950. James Currey, London.

Maloiy, G.M.O., Rugangazi, B.M. \& Rowe, M.F. (2009) Energy expenditure during level locomotion in large desert ungulates: the one-humped camel and the domestic donkey. J. Zool. 277, $248-255$.

McNaughton, S.J. \& Georgiadis, N.J. (1986) Ecology of African grazing and browsing mammals. Апnи. Rev. Ecol. Syst. 17, $39-65$.

MitchelL, K. (2007) Quantitative Analysis by the Point-Centered Quarter Method. Department of Mathematics and Computer Science, Hobart and William Smith Colleges, Geneva.

Owen-Smith, N. \& Cumming, D.H.M. (1993) Comparative foraging strategies of grazing ungulates in African savanna grasslands. In: Proceedings of the XVII International Grasslands Congress, 8-21 February 1993, Palmerston North, New Zealand. New Zealand Grassland Association, Palmerston North.

PARKER, D.M. \& Bernard, R.T.F. (2005) The diet and ecological role of giraffe (Giraffa camelopardalis) introduced to the eastern Cape, South Africa. J. Zool. 267, 203-2010.

Pellew, R.A. (1983) The giraffe and its food resource in the Serengeti. I. Composition, biomass and production of available browse. Afr. J. Ecol. 21, 241-267.

PeLLEW, R.A. (1984) The feeding ecology of a selective browser, the giraffe (Giraffa camelopardalis tippelskirchi). J. Zool. 202, 57-81.

Pringle, R.M., DoAk, D.F., Brody, A.K., Jocoue, R. \& Palmer, T.M. (2010) Spatial pattern enhances ecosystem functioning in an African savanna. PLoS Biol. 8, e1000377 [epub ahead of print].

Pringle, R.M., Palmer, T.M., Goheen, J.R., McCauley, D.J. \& KeESING, F. (2011) Ecological importance of large herbivores in the Ewaso ecosystem. In: Conserving Wildife in African Landscapes: Kenya's Ewaso Ecosystem (Ed. N. Georgiadis). Smithsonian Institution Scholarly Press, Washington, DC.

Prins, H.H.T. \& FriTZ, H. (2008) Species diversity of browsing and grazing ungulates: Consequences for the structure and abundance of secondary production. In: The Ecology of Browsing and Grazing (Eds I. J. Gordon and H. H. T. Prins). SpringerVerlang, Berlin.

RETZER, V. (2006) Impacts of grazing and rainfall variability on the dynamics of a Sahelian rangeland revisited (Hein, 2006): new insights from old data. J. Arid Environ. 67, 157-164.
Sinclair, A.R.E. (1979) Dynamics of the Serengeti ecosystem: process and pattern. In: Serengeti: Dynamics of an Ecosystem (Eds A. R. E. Sinclatr and M. Norton-Griffiths). University of Chicago Press, Chicago, IL.

DU TorT, J.T. (1990) Feeding-height stratification among African browsing ruminants. Afr. J. Ecol. 28, 55-61.

DU TorT, J.T. (1995) Determinants of the composition and distribution of wildlife communities in southern Africa. Ambio 24, 2-6.

Treydtea, A.C., van der Beekb, J.G.M., Perdokb, A.A. \& van Wierenb, S.E. (2011) Grazing ungulates select for grasses growing beneath trees in African savannas. Mamm. Biol. 76, 345-350.

Tutchings, A., Fennessy, S., Marais, A. \& Fennessy, J. (2013) Africa's Giraffe Giraffa Camelopardalis: A Conservation Guide. Giraffe Conservation Foundation, Eros, Namibia.

Woolnough, A.P. \& DU Tort, J.T. (2001) Vertical zonation of browse quality in tree canopies exposed to a sizestructured guild of African browsing ungulates. Oecologia 129, 585-590.

Young, T.P. \& IsBelL, L.A. (1991) Sex differences in giraffe feeding ecology: energetic and social constraints. Ethology 87, 79-89.

Young, T.P., Stubblefield, C.H. \& IsbelL, L.A. (1997) Ants on swollen-thorn acacias: species coexistence in a simple system. Oecologia 109, 98-107.

Young, T.P., OKello, B., Kinyua, D. \& PALmER, T. (1998) KLEE: A long-term multi-species herbivore exclusion experiment in Laikipia. Kenya. Afr. J. Range For. Sci. 14, 92-104.

Young, H.S., McCauley, D.J., Helgen, K.H., Goheen, J.R., OtárolaCastillo, E., Palmer, T., Pringle, R.M., Young, T.P. \& Dirzo, R. (2013) Effects of mammalian herbivore declines on plant communities: observations and experiments in an African savanna. J. Ecol. 101, 1030-1041.

(Manuscript accepted 30 November 2014)

doi: 10.1111/aje.12204

\section{Supporting information}

Additional Supporting Information may be found in the online version of this article:

Table S1 Methods used to collect data for each research question.

Table S2 Statistical tests used to analyze data for each research question.

Table S3 Giraffe feeding height categories and measurements.

Table S4 Camel feeding height categories and measurements.

Table S5 Numbers of tracked and composite giraffe. 
Table S6 (a) Pooled adult giraffe feeding heights. (b) Adult giraffe feeding heights by sex.

Table S7 Camel feeding heights.

Table S8 (a) Total number of plants measured for height on PQ transects $(\mathrm{n}=1452)$. (b) Plant species Mean, Median \& SD height $(\mathrm{m})$.
Figure S1 Flow chart detailing the method and data recorded during giraffe behavioral observations.

Figure S2 Photo illustration of how the vehicle-based GPS waypoints of giraffe encounters were moved using field metadata and ArcGIS trigonometry to represent the real location of the giraffe in space (not to scale). 